Philip Kirkman \& S. Brownhill (2020): Refining professional knowing as a creative practice: towards a framework for SelfReflective Shapes and a novel approach to reflection, Reflective Practice, DOI: 10.1080/14623943.2020.1712195

\title{
Refining professional knowing as a creative practice: towards a framework for Self-Reflective Shapes and a novel approach to reflection.
}

\author{
Authors \\ Phil Kirkman drpkirkman@gmail.com \\ Simon Brownhill
}

\begin{abstract}
:
This paper introduces a theoretical framework for the Self-Reflective Shapes approach, a creative solution that was developed in response to a practical challenge of supporting the development of a culture of reflection. We frame the problem empirically by outlining the context of our work with Kazakhstani teacher-trainers and theoretically by examining conceptions of professional knowing and reflection that can lead to the overemphasis of either explicit, well-defined knowledge outcomes or tacit, illdefined embodied knowledge. Drawing on diverse reflective traditions, in this context reflection is focused on developing the freedoms necessary to successfully meet competing educational demands, be they academic, standards-based, developmental, or social-transformational in nature. We propose that acts which balance freedoms and constraints are inherently creative and therefore reflection can be seen as a creative act. This in turn offers a vehicle to manage tensions that arise from the divergent pressures which arise across educators' experiences. Self-Reflective Shapes is presented as an example of such a creative approach as it empowers teachers to focus on the tensions and intentions that are of greatest concern in their context as well as addressing the need to simultaneously develop diverse knowledge forms when addressing multiple, ill-defined and competing educational problems.
\end{abstract}

\section{Introduction}

With the persistent demand for quality provision in education across the globe, the call for reflective educators remains ever present (Krishnaratne et al. 2013). Reflective practice is widely recognised as an essential tool for supporting the development of educators, helping to inform change and improve practice (Moon, 2004). Arguments for the use of reflective practice in support of teacher development in education are well rehearsed in professional and academic arenas (Soomro, 2018). Finlay (2008, p.1) 
proposes a level of consensus around notions of reflection that includes individual practitioners being self-aware and critically evaluating their responses to practice situations. It is this notion of self-reflection in support of teacher development to which this paper focusses its attention.

Mitchell (2017, p.166) asserts that '[t]eaching reflective practice is not easy, nor is engagement with the reflective process.' This was certainly true of tutors' experiences of working with Kazakhstani trainers as part of the in-service NIS Centre of Excellence training. As part of a Kazakhstan-wide programme of educational development visits, tutors from the UK visited the NIS Centre of Excellence headquarters in Astana to offer support to Kazakhstani teacher-trainers with training across a wide range of areas including reflective practice (see Wilson et al., 2013 for further details). Informal observations in taught sessions highlighted that Kazakhstani professionals were struggling to engage in the reflective process, merely describing what they had done with educators in a variety of educational settings (Mortari, 2015) as opposed to employing 'analysis, synthesis and evaluation' to gain a deeper critical understanding of their experience (Cole, 2000, p.32).

It was noted that many of these practicing teacher-trainers were knowledgeable in their field, were skilled communicators and were already perceived as effective trainers in their context. Yet, participants in the programme also exhibited pedagogies that prized reified knowledge over understanding and application, generic 'best practice' over personalized and differentiated approaches, and which were struggling to move beyond the well-established culture of passivity and compliance (Wilson et al., 2013; Turner et al. 2017). For example, during peer assessment sessions a common response to requests for feedback about areas for improvement in their own and other trainer's work was to pivot back onto previously mentioned successful features or to rearticulate descriptive success criteria without reference to any specific work. Efforts to probe the trainers' thoughts and understanding were constantly greeted with a sea of verbalised positivity which appeared to serve as a protective veneer that avoided the expression of any issues or weaknesses that may have been perceived as 'failure' by their peers (Helyer, 2015). This lack of honesty and openness, which Knutsson et al. (2015, p.459) identify as being two reflective 'learning prerequisites', meant that only a "surface level" of reflection was shared in both oral and written form with peers and the tutors (Ryken and Hamel, 2016), thus limiting the Kazakhstani trainers' reflection to more of the who and the what as opposed to the how and the why (Jasper, 2011).

To understand why trainers were experiencing such difficulties, reference was made to the work of Burkhalter and Shegebayev (2010) who acknowledge that reflection was not a prominent feature of Soviet pedagogy. This gave a firm footing to our emerging 
experiences which suggested that the process of learning through reflection was not something that many Kazakhstani trainers had previous experience of, understood or had been taught to use. In this way, it became clear that that a structured approach to reflective practice would be necessary which attended to their development needs in a culturally appropriate manner. Thus, we were faced with the challenge of balancing the need to support processes of reflection with the need to avoid it becoming a prescribed formula for 'best practice.' Put another way, we needed to ensure that reflection remained an exploratory endeavour.

The following sections will outline will develop a framework that responds to this challenge and positions the development of professional knowing as a creative practice. This works towards presenting the Self-Reflective Shapes approach as a solution to the need to support Kazakhstani trainers in moving beyond uncritical and passive approaches to reified knowledge.

\section{Reflection and professional knowing.}

At a basic level reflection is something that we do implicitly as part of being human, 'underpinning our identities through a process of negotiation between our sense of self and our experiences of others' (Demetriou, 2000, p.210). This notion is afforded weight in Dewey's (1933) frequently cited view of reflection as an everyday habit that is complex, rigorous and intellectual and which 'takes time to do well.' (Rodgers, 2002, p.844). Schön's (1983) pervasive model proposes two types of reflective action: i) reflection on knowing which involves looking back, and ii) reflection-in-action: which involves reflecting whilst in engaged in the activity. Hébert (2015) highlights the contrasting aspects of these perspectives in her characterisation of them as rationalisttechnicist and experiential-intuitive respectively. However, notably, she also suggests that both models separate knowledge and experience in their own way in order to privilege knowledge over experience. She suggests that pathic knowing is the epistemological foundation of tacit knowledge and is a bodily act rather than a cognitive one. In turn proposing that a pedagogy which engages with this kind of tacit knowing can help to recapture experiential-intuitive knowing. Yet, this characterisation of 'pathic knowing' is in danger of falling into the same Cartesian dualism that Bleakley (1999) suggests is evident in attempts to propose models of reflective practice. In contrast, given the 'interrelated' nature of existence (Gendlin, 1979, p.43), pathic knowing is at once both a bodily and cognitive act. Thus, understanding that involves tacit knowing also necessitates attention also to thought and articulation/expression (ibid.). In the light of this, the challenge for educators is how to foster the kind of professional knowing which connotes explicit and tacit knowing; cognitive and bodily acts; knowledge and experience. 
The work of Kolb (2015) develops the relationship between knowledge and experience by proposing reflection as a mental activity that has a role in learning from experience. Whilst there are numerous critiques of these notions of reflection (e.g. Johns, 2006) there is broad agreement across these and other models that reflection is not only personal and recursive in nature, but is also made up of a number of sequential 'never-ending' stages or phases - (Greenaway, 2002; Gibbs, 1988). Nevertheless, there are outstanding questions in relation to the temporal displacement of the cognitive from the embodied aspects of this model.

\section{Self-reflection}

Focusing on self-reflection offers the potential to address some of the challenges noted above, as rather than emerging from the separation of knowledge and experience it draws on teachers' lived experiences. Lew and Schmidt (2011a) argue that self-reflection has received numerous definitions and thus any effort to develop self-reflective practice requires clarification as to its meaning. Efforts to define the term 'self-reflection' within educational environments suggest that it is 'thinking over one's own actions and acting in interaction with pupils' with an emphasis being placed on 'the teachers' inner dialogue with him/herself' (Švec, 2005, p.78). This highlights that self-reflection can take place in action as well as on-action. Gillespie (2007, p.678) emphasizes the experiential nature of self-reflection in description of it as 'a temporary phenomenological experience in which self becomes an object to oneself.' Through this 'experience' that individuals can reflect 'upon their learning, which includes their personal experiences, perspectives, beliefs and claims' (Shaw et al., 2018, p.2). Their description of selfreflection regards it as a process that allows students, for example, opportunities to be reflective about the learning that has taken place. Illumination of this process is offered by Yip who regards self-reflection as a critical analysis of an individual's practice: (S)he relates his or her practice to personal, situational ... and contextual factors. The[y] ... may engage in a process of self-analysis by examining his or her personal attributes (feelings, personality, interest, preferences, background and experience) in response to external factors (social and cultural environments, ... agency and service contexts) (2006, p.780). Synergies with the notion of learning through practice are noted in the thinking of Lew and Schmidt (2011b), who argue that self-reflection is facilitated by two connected processes, especially in the context of trying to improve academic achievement; this is presented in Figure 1.

\section{INSERT FIGURE 1}

Acknowledging self-reflection as 'a process' would suggest that self-reflection is not 'a product' with a fixed endpoint. However, Schön highlights that embodied rather than 
articulated knowledge is developed through intentional restructuring and thus 'selfreflection 'stops' when professionals cease being purposely self-reflective' (Author, b, p.132). Thus, it can be argued that a key challenge for educators is not stopping but continuing to actively engage in purposeful self-reflection. Indeed, Driessen et al. (2008: 829) suggest that some professionals 'will not generally do it automatically'.

It may be argued that defining self-reflection as a purposeful activity negates the possibility of moving beyond technical-rationality (Hébert, 2015). However, action can be both purposive and towards an ill-defined goal (Johnson-Laird, 1988). This is possible if the focus of the reflection is towards an individual's (ill-defined) personal developmental process. Thus, self-reflection can be seen as a purposeful process of selfexperience and -analysis that involves critical thought as well as personal attributes and external factors in response to an ill-defined problem. This construction of self-reflection may offer a means to move towards professional knowing which connotes explicit and tacit knowing, knowledge and experience.

\section{The educational context}

Having noted the challenges when working with Kazakhstani trainers and having outlined a notion of self-reflection that offers opportunities to move beyond notions of reflection that neglect more experiential and tacit aspects of professional knowing, we will now turn our attention to systemic challenges that can underpin educators' resistance to the self-reflective process defined above.

There are systemic challenges, faced by educators across the world, not least in the Kazakhstani context, that can disrupt this self-reflective process. These are most easily understood through brief look at the legacy of technical-rationality across education systems. The enduring legacy of this epistemology across policy and educational leadership contexts is that practitioners continue to express concerns with being asked to apply 'research-based', 'proven', 'technical' knowledge (EEF, 2019) that are too detached from practice (TDBRC, 2003). More recently this tension can be seen in responses to international projects such as Hattie's Visible Learning (2008) and the Teaching and Learning Toolkit, (EEF, 2019) which enjoy seemingly unprecedented and often uncritical favour (Myburgh, 2016) as policy-makers and school leaders use 'the research' to target resources on developing what are proclaimed as the 'best low cost proven approaches' (Sutton Trust and Education Endowment Foundation, 2015 p.8). As Schön (1983) argued, the effect of the underlying epistemology is that it fosters a view of reflection as 'an application of knowledge to instrumental decisions' (p.50) and professional knowledge as knowledge about 'what works'. Furthermore, applying technical knowledge in professional contexts leads to several misunderstandings that 
see certain aspects of practice as 'limitations' (ibid.); namely that practice is divergent, practice has unstable contexts and ill-defined outcomes and that practice does not focus on problems or solutions'.

Attempts to generate solutions to these limitations encourages convergence towards homogeneous approaches which are evaluated in terms of the rudimentary yet clear and stable outcomes of cost and attainment and offers seductively simple solutions to the manifest, enduring and ethical dilemma; the problem of how best to focus limited educational resources to achieve measurable outcomes. Taking the Teaching and Learning Toolkit (EEF, 2019) as an example, it is clear to see that within this resource, solutions are offered at a national scale in relation to measurable investment and outcomes. While these projects are helpful in as much as they have developed ways of drawing together theoretical understanding about the effects of certain approaches on a macro scale, relying on this kind of knowledge leaves us with two significant shortcomings. The first is that focusing on cost and attainment as the only measures of success can encourage schooling that neglects the more ill-defined and holistic aspects of education (Niyozov \& Hughes, 2019) and encourages an unhelpful hierarchy of subjects (Bleazby, 2015). The second is that using an evidence base which relies on large scale statistical modelling cannot account for individual variations in practice at a school, classroom or student level and crucially obscures the notion explored above; namely that reflection is a personal and subjective, cyclic and recursive process.

This, was reflected in the experiences of the Kazakhstani teacher-trainers whose need to maintain a protective veneer was directly related to externally imposed measures of success (Turner et al., 2017) that were driven by cost, attainment and the legacy of a heavily standardized system. Analysis of these tensions - between the need to develop personal practice through openness and honesty and the need to 'be successful' in terms of external measures - revealed that the key challenge was not with the process of reflection itself but rather with the divergent and competing purposes of reflective processes. For example, if teacher-trainers read that 'Feedback is the most effective educational 'approach' in terms of its impact on outcomes (EEF, 2019) they were then less able to consider questions such as: "What might the feedback look like?; How might it be communicated?; Does all feedback work?; Is some more helpful than others?; Is it helpful for all students?; In what ways?; etc.. Instead the priority was to 'be successful' and to perform success by re-asserting that 'Feedback is the most effective educational 'approach'. The more subtle questions were left unanswered. Individual teachers need to know how to formulate answers to questions like these to make informed but necessarily subjective decisions about how to work in their classrooms, and the intention of our support for self-reflective practice was to help develop the professional knowledge necessary to address these questions. Thus, there was a 
mismatch between the intentions of the reified knowledge available to Kazakhstani educators as they made decisions about how to act and the knowledge they needed to respond to educational dilemmas in specific contexts. One focuses on generalities, the other specifics; one considers success in terms of economics and large-scale trends, the other success in terms of individual learner development.

\section{Towards a solution: four traditions of reflection}

We address this mismatch we return to the intentions of reflection, seen across four well-established traditions. This approach allows us to refine the act of professional knowledge as a creative, embodied act of explicit and tacit knowing that involves mind and body; knowledge and experience. This, in turn, allows us to articulate the selfreflective shapes approach as a solution to our practical education problem (see introduction).

Tabachnick and Zeichner (1991) suggest four contrasting traditions of reflection that highlight different ways in which reflective practices have been employed in the pursuit of professional knowledge; these include i) the Academic tradition, ii) the Social Efficiency tradition, iii) the Developmentalist tradition. and iv) the Social Reconstructivist tradition. Zeichner and Liston (1990) had previously developed these categories in response to the tensions and conflicts that were impeding reform across teacher education programmes describing the confusion about the underlying assumptions of popular terms that were used within the teaching community. From a contemporary perspective, the notion of conceptual ambiguity around reflection is also shared by Marshall (2019), although his focus is on defining processes of reflection as opposed to identifying traditions of reform. Tabachnick and Zeichner's (1991) approach highlights that the specific intention of reflective activity is just as important as the process of reflecting and suggests that if we are to engage in well-defined reflection we need to acknowledge that both the personal intention of the act and the features of the educational context in which it takes place are implicated in the shape of the process. Thus, as we discuss Tabachnick and Zeichner's (1991) four traditions, we will note both their intentions and contexts.

The Academic orientation highlights the teacher's role as a specialist in transforming subject knowledge. In this tradition, reform was concerned with promoting student understanding by using pedagogic knowledge to transform subject knowledge. The intention of reflection was to challenge the historically more dominant 'academic reform' perspective that 'more subject knowledge is better'. 
The Social Efficiency tradition emphasizes the intelligent use of research to inform decisions about employing the 'skills and competences that research has shown to be associated with desirable pupil outcomes' (p.6) and to establish principles of procedure. The intention of reflection lies on a continuum between fostering teachers' capabilities to make informed judgements about using different approaches to achieve the goals of education on the one hand and considering how their practice conforms to generic standards on the other.

The Developmentalist tradition of reform is concerned with the natural development of learners and with the ways in which 'what' and 'how' subject matter is taught responded to the needs and behaviour of learners. Tabachnick and Zeichner (1991) highlight three metaphors within this tradition:

i) the teacher as naturalist - emphasizing the importance of teachers' skills in observing and responding to students needs;

ii) the teacher as researcher - stressing the importance of developing appropriate responses to observations through experimental case work; and

iii) the teacher as artist - highlighting the need for creative teachers and stimulating classrooms.

Reflection in this tradition is about working to consider students' learning. The intention of reflection is to move from less to more responsive, targeted, creative and stimulating classrooms.

The Social Reconstructivist tradition of reform focuses on the need for education to help address societal injustice around issues such as class, race and gender. This tradition recognizes the intrinsically political nature of schooling the ways in which schooling contributes to or disrupts social equity and injustice. Reflection within this tradition focusses inwardly at a teacher's own practice and outwardly at the social conditions in which these practices are situated. Reflection moves teachers who are less aware and compliant towards educators who are increasingly sensitive and responsive to issues of social equity and injustice. The intention of reflection is to increasingly disrupt the constraints imposed on students by the status quo with the purpose of achieving a more just society in the form of emancipated students.

Notably, all these traditions can be considered in terms of the way they highlight that acts of educating are situated in positions of tension between competing freedoms and constraints. Reflection across all four traditions is concerned with addressing both the structural constraints of the environmental contexts in which it takes place, and to develop the teacher agency necessary to successfully meet competing educational 
demands through intentional acts of professional knowing. The academic tradition contrasts the constraint of the historical belief that more knowledge is better with the freedom to decide, promoting student understanding that pedagogic knowledge brings to teachers. The social efficiency tradition distinguishes between the constraints of conforming to standards with the freedoms of making decisions about different approaches and their relationship with the means and ends of education in a given context. The Developmentalist tradition highlights the constraints of rigid and insensitive contexts with the freedoms of a responsive and stimulating environment. The Social Reconstructivist tradition explicitly emphasizes the constraints of culture and context with the purpose of freeing individuals from the injustice within the status quo. Yet, while each tradition of reflection seeks to develop practice by supporting the development of certain freedoms it also threatens to constrain practice if the outcome is perceived as fixed, prescribed or externally measurable. Furthermore, reflective processes may look very different depending on an individual's context.

\section{Refining professional knowing as a creative practice}

To help the Kazakhstani teacher-trainers to understand reflection we needed to address this tension between competing freedoms and constraints that arise from individual contexts. Thus, we needed an approach that simultaneously allows multiple possible different outcomes in response to multiple, ill-defined and competing problems. Thus, we turned to notions of development in creativity which deals directly with individual approaches to balancing the freedoms and constraints offered by diverse traditions (Burnard, 2012).

We defined acts of professional knowing as creative acts. In so doing, we highlighted the need to attend to explicit and tacit knowing, mind and body, and knowledge and experience as these aspects are central to creative practice (Bonnet, 1994). Furthermore, within the context of creative acts, constraints, such as knowledge or standards, are transformed into scaffolding that can help to structure the creative process of decisionmaking (Johnson-Laird, 1988). Thus, positioning acts of professional knowing as creative acts highlights that contextual constraints, such as reified knowledge or external standards became supportive rather than prescriptive in the processes of decision making. These aspects of practice are well-established in creativity literature (Mumford \& Hemlin, 2017; Burns, Machado and Corte, 2015). Table 1 shows the key constraints of each reflective environment noted in Tabachnick and Zeichner's (1991) four reflective traditions alongside the respective freedoms intended through reflection 
and maps these onto the features of creative acts. Viewing reflection as a creative act highlights the different scaffolding that was identified in the current educational environment. This, in turn, revealed how teacher knowing could be transformed through reflection as a creative-act. In transcending the need to atomize reflection into any one tradition and in positioning it as a developing way of knowing, the construction of reflection as a creative practice of professional knowing is well-matched to complex natural contexts of teaching and by extension of personal and social reflection.

\section{INSERT TABLE 1}

Given the framework (above) which reveals how reflection can be understood as a creative act of professional knowing, we will now turn to the specific example of SelfReflective Shapes. This will serve to demonstrate how creative reflection practices can help teachers to balance the tensions noted above and, in the case of the Kazakhstani trainers, move beyond their focus on an uncritical approach to knowledge, best practice and passive compliance.

\section{The emergence of the Self-Reflective Shapes Approach}

The idea of Self-Reflective Shapes emerged from a process of reflection-in-action (Schön, 1983) and reflection-for-action (Killion and Todnem, 1991). When working directly with a group of Kazakhstani trainers, tutors noted their discomfort at being asked to reflect on their recent experiences of working with professionals in a variety of educational settings. Confused facial expressions, averted eyes and closed body language suggested that this was an uncomfortable activity. This assertion was validated by the interpreter who reported that participants were happy to tell others about their lived experiences (what happened) but they were reluctant to acknowledge aspects of their experience which were not successful ("Everything is positive!"), nor were they clear on what they had to do/think when tutors asked them to reflect on why they thought things had happened the way they had and what they would do differently if they were able to engage in the experience again. Lists of translated reflective questions were offered to trainers in written form to promote critical discussion in small groups but these merely served to compound their confusion, with trainers asking tutors to 'tell them what to think/say' in response to select questions rather than their responses being drawn from their own understanding and thought. Anxious reflections following this experience led to the construction of a practical way to individually support teacher-trainers to engage more confidently in reflection by breaking the process up into small parts whilst responding positively to their noted passion for visually capturing their learning through drawings, diagrams and colourful images. Subsequently, the idea of Self- 
Reflective Shapes was shared with Kazakhstani trainers to engage them in in acts of professional knowing that were orientated towards self-development rather than group focused work that was orientated towards passive knowledge telling of 'best practice.

Self-Reflective Shapes initially requires the individual to select and draw any twodimensional shape on a piece of paper or on a technological device. The chosen shape can be regular in construct - think a star/rainbow/diamond/cloud/arrow/lightning bolt or irregular; it can have personal meaning to the self-reflector (e.g., a heart) or be random in selection. For the purposes of explanation a flower head has been selected (see Figure 2).

\section{INSERT FIGURE 2}

Self-reflectors are then required to segment the two-dimensional shape into separate 'compartments' with lines - these can particular qualities chosen by the self-reflector, e.g. thin, straight, broken, crossing over one another. Figure $X$ works well as a SelfReflective Shape because each petal helps to effectively break the overall flower head up into six separate parts.

The self-reflector then identifies which questions they would like to ask themselves. These questions can come from known reflective cycles (e.g., Gibbs, 1988), publications (journal article-based - see Moussa-Inaty, 2015), online sources, or they could be selfdevised (see figure 3 ).

\section{INSERT FIGURE 3}

Once a number of questions have been identified/formulated (as many or as few as the self-reflector wishes to focus on), self-reflectors then use these to help them self-reflect on their learning from any of the following: a professional experience, an event/critical incident, a conversation, an observation, a review of their progress, or a personal practice. In response to their selected questions, self-reflectors are encouraged to commit their own self-reflective thoughts within the spaces provided by the individual compartments of their Self-Reflective Shape - these thoughts can be recorded in the form of words, phrases, full sentences, "speech", drawings/sketches, doodles, symbols, colours, codes or shapes - anything that has personal meaning to the self-reflector. To illustrate this, Figure 4 offers an example of one such shape:

\section{INSERT FIGURE 4}




\section{Lessons from Self-Reflective Shapes}

Thinking back to our framework (table 1) which outlines how creative reflection practices can help teachers to balance the tensions between developmental objectives, there are several features of the Self-Reflective Shapes approach that promote the development of professional knowing as a creative practice. These are highlighted in table 2:

INSERT TABLE 2

The final column of the table shows how self-reflective shapes presents opportunities to focus on the development of professional knowledge that acknowledges the requirement for teachers to balance knowledge that is explicit and tacit, personal and social, problem-solving with creative and conforming with disruptive. In selecting their own shape and defining their own 'constraints', and in selecting their own reflective questions, teachers are empowered to focus on and represent the tensions and intentions that are of greatest concern in their current practice. By facilitating non-verbal responses to these tensions, the self-reflective process overcomes the need to atomise them and thus promotes more naturalistic intuitive and 'artistic' (Schön, 1983) responses. Notably also, this reflective approach is inherently less threatening as the teacher's self-selected responses can be well- or ill-defined and as meanings can be covert or can remain tacit. Yet, the structured nature of the approach encourages teachers to participate in an intentional process of thinking and acting (Švec, 2005). Through subsequent practice and discussion exploring these meanings, a self-reflective shapes approach can also help to transform tacit into explicit knowledge.

In the case of the Kazakhstani teacher-trainers it was the case that this approach helped to start the process of developing a professional reflective culture of honesty and openness that also allowed them to manage external demands by maintaining their protective veneer. While it is true that not all the participants came to see beyond the pervading culture and longstanding habits, it is that case that individual teachertrainers continued their process of professional development with a renewed awareness of the freedoms that they could enjoy as creative-reflective professionals. Limitations of the approach include the continued emphasis on representations of practice that can drift away from acknowledging the importance of tacit knowledge and the potential for this approach to be exploited by trainers who may resist critical depth. Nevertheless, 
these limitations are also true of language and action so it is hoped that this approach may at least offer a step in the right direction.

\section{Conclusion}

In refining acts of professional knowing as creative practices, we hope to foster debate about the intentions and environments of reflection. Self-reflective shapes is presented as one such creative approach to reflection. It is clear that teachers work in complex contexts of competing freedoms and constraints. It is also the case that they face increasing pressures from the growing availability and power of big data and its associated reified knowledge. Informed discussions about the complex intentions of educational acts and their impact on individuals has always been a necessary precursor to strategic development. Thus, we would argue that there has never been a more vital time to empower teachers to make informed judgements about how to foster student understanding, to foster sensitive, differentiated and stimulating learning environments and to disrupt the injustices inherent in the constraints of educational contexts. Having presented a framework that positions reflection as a creative act of professional knowing and having outlined self-reflective shapes as one practice-led approach that may offer the potential to support the development of such practice, further research is now required into teachers' experiences of this approach, its utility in different educational environments and on the impact of this approach on student attainment outcomes as well as on the more personal social and emotional aspects of development.

\section{Acknowledgements}

The Authors wish to thank the NIS Centers of Excellence teacher participants for their participation during the development of the Self-Reflective Shapes approach.

\section{References:}

Bleakley, A., (1999). From reflective practice to holistic reflexivity. Studies in Higher Education, 24, 315-330.

Bleazby, J. (2015). Why some school subjects have a higher status than others: The epistemology of the traditional curriculum hierarchy. Oxford Review of Education, 41(5), 671-689.

Bonnett, M. (1994) Children's Thinking . London: Cassell 
Brownhill, S. (2014). Supporting teachers' reflective practice through the use of selfreflective shapes. Pedagogical Dialogue, 4(10), 132-135.

Burkhalter, N., \& Shegebayev, M. (2010). The Critical Thinking Movement in Kazakhstan: a progress report. Research in Comparative and International Education, 5(4), 434-445.

Burns, T. R., Machado, N., \& Corte, U. (2015). The sociology of creativity: Part I: Theory: The social mechanisms of innovation and creative developments in selectivity environments. Human Systems Management, 34(3), 179-199.

Burnard, p. (2012). Musical Creativities in Practice. Oxford: Oxford university Press.

Cole, M. (2000). Learning through reflective practice: a professional approach to effective continuing professional development among healthcare professionals. Research in PostCompulsory Education, 5(1), 23-38.

Demetriou, A. (2000). Organization and development of self-understanding and self-regulation: towards a general theory. In M. Boekaerts, P. R. Pintrich, \& M. Zeidner (Eds.), Handbook of SelfRegulation (pp. 209-251). London: Academic Press.

Dewey, J. (1933). How We Think. Boston: D.C. Heath \& Co., Boston, MA.

Driessen, E., Tartwijk, J. v., \& Dornan, T. (2008). The self-critical doctor: helping students become more reflective. British Medical Journal, 336(7648), 827-830.

EEF. (2019). Teaching and Learning Toolkit. Retrieved from https://educationendowmentfoundation.org.uk/evidence-summaries/teaching-learningtoolkit

Finlay, L. (2008). Reflecting on 'Reflective Practice'. PBPL paper 52 (January), pp.1-27. Retrieved from https://pdfs.semanticscholar.org/2988/c18f4f2735108553f46f628fe285a2287226.pdf?_ga=2. 16193462.1056767802.1576748390-518933599.1567181526

Gendlin, E.T. (1979). Befindlichkeit: Heidegger and the philosophy of psychology. Review of Existential Psychology and Psychiatry 16(1-3) 48-60.

Gibbs, G. (1988). Learning by Doing: A guide to teaching and learning methods. Oxford: Further Education Unit, Oxford Polytechnic. 
Gillespie, A. (2007). The social basis of self-reflection. In J. Valsiner \& A. Rosa (Eds.), The Cambridge Handbook of Sociocultural Psychology (pp. 678-691). Cambridge: Cambridge University Press.

Greenaway, R. (2002). Experiential Learning Cycles. Retrieved from http://reviewing.co.uk/research/learning.cycles.htm

Hattie. J. (2008). Visible learning: A synthesis of over 800 meta-analyses relating to achievement. London: Routledge.

Hébert, C. (2015). Knowing and/or experiencing: a critical examination of the reflective models of John Dewey and Donald Schön. Reflective Practice: International and Multidisciplinary Perspectives, 16(3), 361-371.

Helyer, R. (2015). Learning through reflection: the critical role of reflection in workbased learning (WBL). Journal of Work-Applied Management, 7(1), 15-27.

Jasper, M. (2011). Professional Development, Reflection and Decision-making (2nd ed.). Oxford: Blackwell Publishing.

Johns, C. (2006). Engaging reflection in practice: A narrative approach. Oxford: Blackwell Publishing.

Johnson-Laird, P. (1988). The Computer and the Mind: An Introduction to Cognitive Science. Cambridge, MA: Harvard University Press.

Killion, J., \& Todnem, G. (1991). A process of personal theory building. Educational Leadership, 48(6), 14-17.

Knutsson, S., Jarling, A., \& Thorén A-B. (2015). 'It has given me tools to meet patients' needs': students' experiences of learning caring science in reflection seminars. Reflective Practice: International and Multidisciplinary Perspectives, 16(4), 459-471.

Kolb, D. (2015). Experiential Learning: Experience as the Source of Learning and Development. New Jersey: Pearson Education Ltd.

Krishnaratne, S., White, H., \& Carpenter, E. (2013). Quality education for all children? What works in education in developing countries. New Delhi, India: International Initiative for IMsPAct Evaluation. 
Lew, D. N. M., \& Schmidt, H. G. (2011a). Writing to learn: can reflection journals be used to promote self-reflection and learning? Higher Education Research \& Development, 30(4), 519532.

Lew, D. N. M., \& Schmidt, H. G. (2011b). Self-Reflection and Academic Performance: Is There a Relationship? Advances in Health Sciences Education, 16(4), 529-545.

Marshall, T. (2019). The concept of reflection: A systematic review and thematic synthesis across professional contexts. Reflective Practice: International and Multidisciplinary Perspectives, 20(3), 396-415.

McNeill, D. (2000). Language and Gesture. Cambridge: Cambridge University Press.

Michell, V. A. (2017). Diffracting Reflection: A Move Beyond Reflective Practice. Education as Change, 21(2), 165-186.

Moon, J. (2004). A Handbook of Reflective and Experiential Learning: Theory and Practice. London: Routledge.

Moore, A. (2004). The Good Teacher: Dominant Discourses in Teaching and Teacher Education. London: Routledge.

Mortari, L. (2015). Reflectivity in Research Practice: An Overview of Different Perspectives. International Journal of Qualitative Methods, 14(5), 1-9.

Moussa-Inaty, J. (2015). Reflective Writing through the Use of Guiding Questions. International Journal of Teaching and Learning in Higher Education, 27(1), 104-113.

Mumford, M., \& Hemlin, S. (Eds.) (2017). Handbook of Research on Leadership and Creativity. Cheltenham: Edward Elgar Publishing.

Myburgh, S. J. (2016). Critique of Peer-reviewed Articles on John Hattie's Use of Meta-Analysis in Education. Working Papers Series: International and Global Issues for Research, University of Bath Department of Education, No. 2016/3 (December). Retrieved from http://www.bath.ac.uk/education/documents/working-papers/critique-of-peer-reviewedarticles.pdf

Niyozov, S., \& Hughes, W. (2019). Problems with PISA: Why Canadians should be skeptical of the global test. Retrieved from http://theconversation.com/problems-with-pisa-whycanadians-should-be-skeptical-of-the-global-test-118096

Rodgers, C. (2002). Defining reflection: Another look at John Dewey and reflective thinking. Teachers College Record, 4(4), 842-866. 
Ryken, A. E., \& Hamel, F. L. (2016). Looking Again at "Surface-Level" Reflections: Framing a Competence View of Early Teacher Thinking. Teacher Education Quarterly, Fall, 31-53.

Schein, E. (1973). Professional Education. New York: McGraw-Hill

Schön, D. A. (1983). The Reflective Practitioner: How Professionals Think in Action. Boston: Arena Publishing.

Shaw, S., Kuvalja, M., \& Suto, I. (2018). An exploration of the nature and assessment of student reflection. Research Matters: A Cambridge Assessment publication, 25, 2-8. Retrieved from https://www.cambridgeassessment.org.uk/Images/475804-research-matters-25-spring2018.pdf

Soomro, A.F., (2018). Evaluating the significance of exploratory practice as an approach to teacher development. Reflective Practice: International and Multidisciplinary Perspectives, 19(4), 461-473.

Sutton Trust and Education Endowment Foundation. (2015). The Pupil Premium Next Steps. Retrieved from https://www.suttontrust.com/wp-content/uploads/2015/06/Pupil-PremiumSummit-Report-FINAL-EDIT.pdf

Švec, V. (2005) Pedagogické znalosti učitele: Teorie a praxe. Praha: ASPI.

Tabachnick, R., \& Zeichner, K. M. (1991). Reflections on Reflective Teaching. In R. Tabachnick, \& K. M. Zeichner (Eds.), Issues and Practices in Inquiry-Oriented Teacher Education (pp. 1-9). London: Falmer Press.

TDBRC. (2003). Design-Based Research: An Emerging Paradigm for Educational Inquiry. Educational Researcher, 32(1), 5-8.

Turner, F., et al. (2017). Details removed for peer review.

Wilson, E., et al. (2013). Details removed for peer review.

Yip, K-s. (2006) Self-reflection in Reflective Practice: A Note of Caution. British Journal of Social Work, 36, 777-788.

Zeichner, K. M., \& Liston, D. P. (1990). Traditions of Reform in U.S. Teacher Education. Journal of Teacher Education, 41(2), 3-20. 
Wordcount: 5902

FIGURES AND TABLES

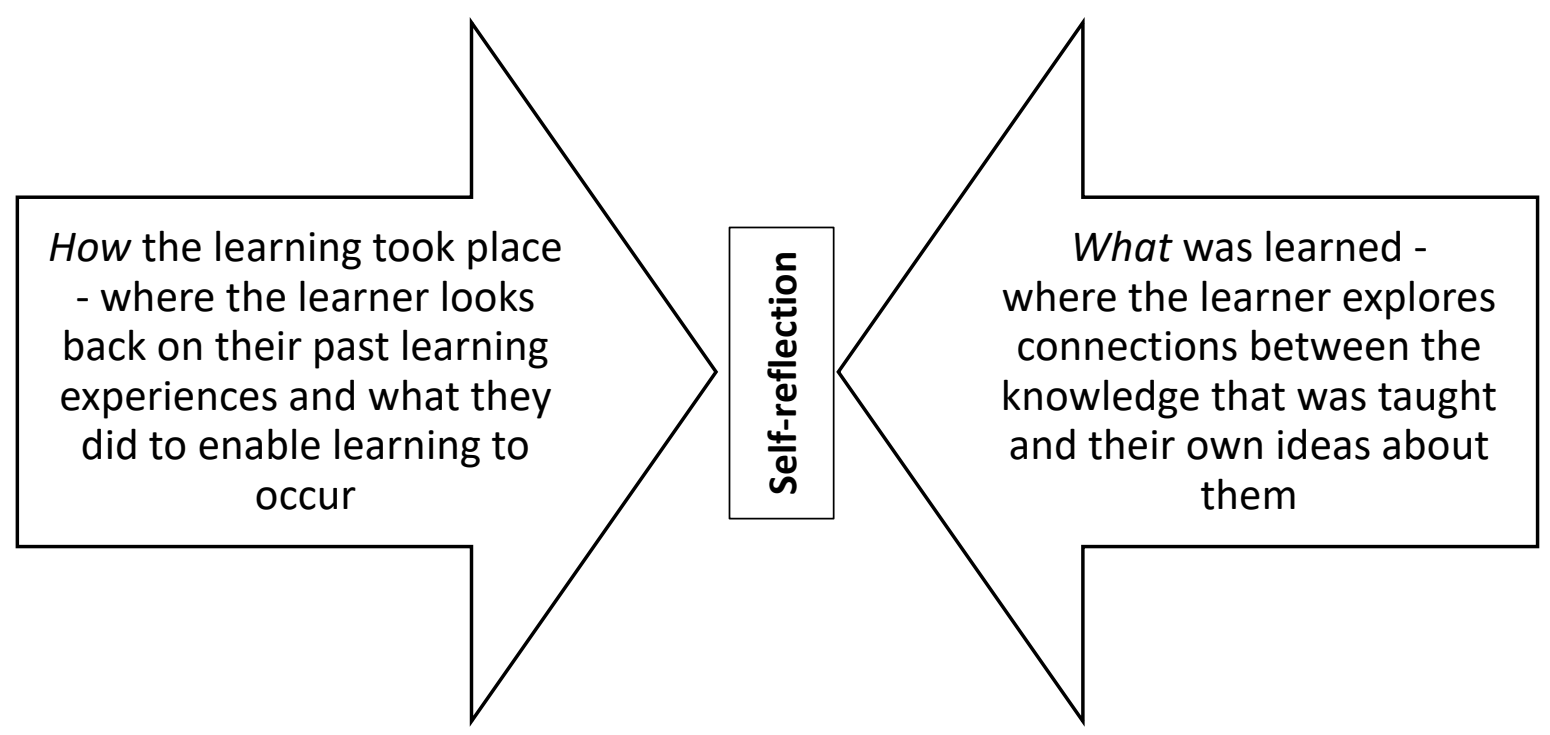

FIGURE 1: Processes involved in self-reflection (Adapted from the work of Lew and Schmidt, 2011a, p.530) 


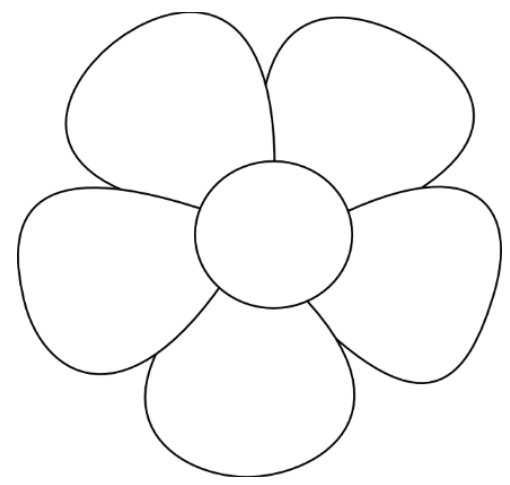

FIGURE 2: An example of a blank Self-Reflective Shape. 
- What actually happened?

- When/where did the event occur?

- What aspects went well? Why did they go well? How do you know - where is your evidence?

- Who surprised/upset you? How did you react to these issues?

- How do you feel now?

\section{FIGURE 3: Example questions for self-reflection.}




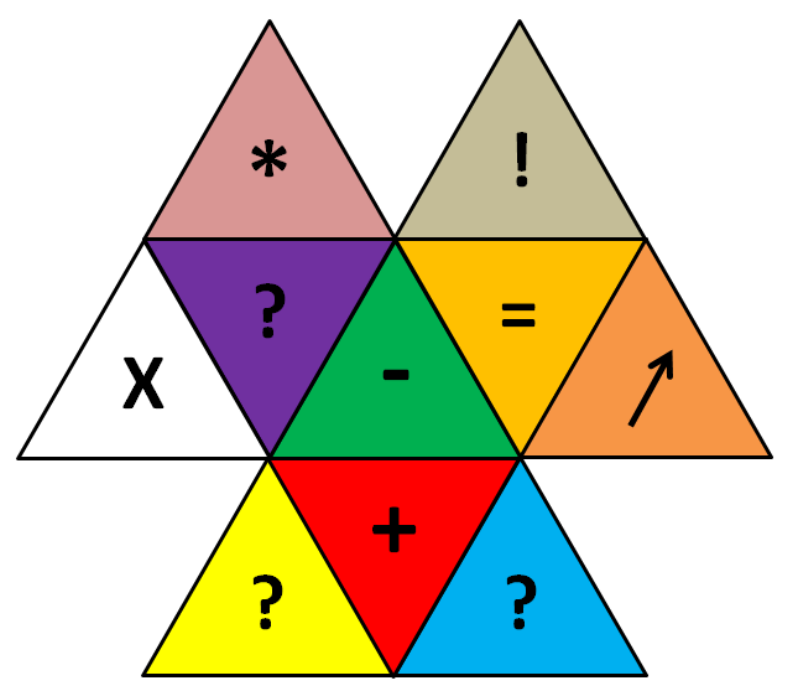

- Start positive $(\operatorname{Red}+)$ - what went specifically well?

- Why did it go well (Yellow ?) and who specifically responded well to it (Blue ?)?

- What did not go particularly well (Green -)? Why did it not go well (Purple ?) and what were the repercussions of this (Orange $=$ )?

- What things were out of my control (White X) and what could I have done differently (Lilac *)?

- What must I remember next time I present (Grey!) and what I have I learned from this experience (Light Brown)?

FIGURE 4: A Self-Reflective Shape with a series of personal question prompts. 


\begin{tabular}{|l|l|l|l|}
\hline $\begin{array}{l}\text { Reflective } \\
\text { tradition }\end{array}$ & $\begin{array}{l}\text { Constraint of the } \\
\text { reflective } \\
\text { environment }\end{array}$ & $\begin{array}{l}\text { Freedom intended } \\
\text { through reflection }\end{array}$ & Features of creative acts \\
\hline Academic & $\begin{array}{l}\text { The perspective that } \\
\text { knowledge is better' } \\
\text { therefore better } \\
\text { teachers deliver more } \\
\text { knowledge. }\end{array}$ & $\begin{array}{l}\text { To transform subject } \\
\text { knowledge to foster } \\
\text { student } \\
\text { understanding. }\end{array}$ & $\begin{array}{l}\text { A) Transforms form and } \\
\text { materials and to shape } \\
\text { and present novel ideas. }\end{array}$ \\
\hline Social Efficiency & $\begin{array}{l}\text { The need for teachers } \\
\text { to consider how their } \\
\text { practice conforms to } \\
\text { generic standards. }\end{array}$ & $\begin{array}{l}\text { Capability to make } \\
\text { informed judgements } \\
\text { about using different } \\
\text { approaches to } \\
\text { achieve the means } \\
\text { and ends of } \\
\text { education. }\end{array}$ & $\begin{array}{l}\text { B) Personal response to } \\
\text { externally defined } \\
\text { standards. }\end{array}$ \\
\hline Developmentalist & $\begin{array}{l}\text { Homogenous, rigid, } \\
\text { undifferentiated }\end{array}$ & $\begin{array}{l}\text { To create sensitive, } \\
\text { differentiated, } \\
\text { creative and exciting } \\
\text { learning contexts. }\end{array}$ & $\begin{array}{l}\text { C) Deals with ill-defined } \\
\text { problems yet clear } \\
\text { contexts and ends. Has } \\
\text { ambiguity of purpose } \\
\text { and is intrinsically } \\
\text { motivating. }\end{array}$ \\
\hline $\begin{array}{l}\text { Sull, uninspiring } \\
\text { educational } \\
\text { demands/contexts. }\end{array}$ & $\begin{array}{l}\text { Unaware and } \\
\text { compliant in relation } \\
\text { to issues of social } \\
\text { equity and injustice } \\
\text { from within culture } \\
\text { and context }\end{array}$ & $\begin{array}{l}\text { To disrupt the } \\
\text { cultural and } \\
\text { contextual } \\
\text { constraints and free } \\
\text { individuals from the } \\
\text { injustice within the } \\
\text { status quo. }\end{array}$ & $\begin{array}{l}\text { D) Disruptive by } \\
\text { fostering knowledge } \\
\text { that is embodied rather } \\
\text { than articulated } \\
\text { developed by } \\
\text { restructuring implicit } \\
\text { understandings }\end{array}$ \\
\hline
\end{tabular}

\section{Table 1: Freedoms and constraints of reflective traditions mapped onto the features of creative acts.}




\begin{tabular}{|c|c|c|c|}
\hline $\begin{array}{l}\text { Reflective } \\
\text { tradition }\end{array}$ & $\begin{array}{l}\text { Freedom intended } \\
\text { through reflection }\end{array}$ & $\begin{array}{l}\text { Features of } \\
\text { creative acts }\end{array}$ & Opportunities in reflective shapes \\
\hline Academic & $\begin{array}{l}\text { To transform } \\
\text { subject knowledge } \\
\text { to foster student } \\
\text { understanding. }\end{array}$ & $\begin{array}{l}\text { A) Transforms } \\
\text { form and materials } \\
\text { and to shape and } \\
\text { present novel } \\
\text { ideas. }\end{array}$ & $\begin{array}{l}\text { Selecting and drawing shapes and } \\
\text { questions involves transforming } \\
\text { both form and materials and offers } \\
\text { opportunity to express and balance } \\
\text { between both explicit and tacit. }\end{array}$ \\
\hline Social Efficiency & $\begin{array}{l}\text { Capability to make } \\
\text { informed } \\
\text { judgements about } \\
\text { using different } \\
\text { approaches to } \\
\text { achieve the means } \\
\text { and ends of } \\
\text { education. }\end{array}$ & $\begin{array}{l}\text { B) Personal } \\
\text { response to } \\
\text { externally defined } \\
\text { standards. }\end{array}$ & $\begin{array}{l}\text { Starting with a directed act of } \\
\text { personal embodied creativity (they } \\
\text { choose and draw their own shape } \\
\text { and choose questions) promotes } \\
\text { balance between } \\
\text { shared/standardized and personal } \\
\text { needs and ends. }\end{array}$ \\
\hline Developmentalist & $\begin{array}{l}\text { To create sensitive, } \\
\text { differentiated, } \\
\text { creative and } \\
\text { exciting learning } \\
\text { contexts. }\end{array}$ & $\begin{array}{l}\text { C) Deals with ill- } \\
\text { defined problems } \\
\text { yet clear contexts } \\
\text { and ends. Has } \\
\text { ambiguity of } \\
\text { purpose and is } \\
\text { intrinsically } \\
\text { motivating. }\end{array}$ & $\begin{array}{l}\text { Using shape, word and image to } \\
\text { express answers affords opportunity } \\
\text { to balance the need to address a } \\
\text { developmental problem (ill-defined) } \\
\text { with the need to establish a creative } \\
\text { and stimulating context. }\end{array}$ \\
\hline $\begin{array}{l}\text { Social } \\
\text { Reconstructivist }\end{array}$ & $\begin{array}{l}\text { To disrupt the } \\
\text { cultural and } \\
\text { contextual } \\
\text { constraints and } \\
\text { free individuals } \\
\text { from the injustice } \\
\text { within the status } \\
\text { quo. }\end{array}$ & $\begin{array}{l}\text { D) Disruptive by } \\
\text { fostering } \\
\text { knowledge that is } \\
\text { embodied rather } \\
\text { than articulated } \\
\text { developed by } \\
\text { restructuring } \\
\text { implicit } \\
\text { understandings }\end{array}$ & $\begin{array}{l}\text { The act of drawing the placeholder } \\
\text { shape and graphic answers can serve } \\
\text { to disrupt the rigid, cultural and } \\
\text { contextual constraints of language. } \\
\text { This balances the need for safety in } \\
\text { conformity in a social reflective } \\
\text { context with the needs to foster } \\
\text { disruptive thinking. }\end{array}$ \\
\hline
\end{tabular}

Table 2: Freedoms promoted through reflection and features of creative acts mapped onto opportunities of self-reflected shapes. 